\title{
SOIL MOISTURE VARIATIONS WITH LAND USE ALONG THE PRECIPITATION GRADIENT IN THE NORTH-SOUTH TRANSECT OF THE LOESS PLATEAU
}

\author{
Cong Wang ${ }^{1,2,3}$, Shuai Wang ${ }^{1,2}$, Bojie Fu ${ }^{1,2 *}$, Lei Yang ${ }^{1}$, Zongshan $\mathrm{Li}^{1}$ \\ ${ }^{1}$ State Key Laboratory of Urban and Regional Ecology, Research Center for Eco-Environmental Sciences, Chinese Academy of Sciences, PO Box 2871 , Beijing \\ 100085, PR China \\ ${ }^{2}$ Joint Center for Global Change Studies, Beijing 100875, PR China \\ ${ }^{3}$ University of Chinese Academy of Sciences, Beijing 100049, PR China
}

Received 17 April 2016; Revised 16 August 2016; Accepted 17 August 2016

\begin{abstract}
Knowledge of soil moisture spatial variation with land use along the precipitation gradient is necessary to improve land management and guide restoration practice in the water-limited Chinese Loess Plateau. This study selected 45 sampling points at 11 sites across the northsouth transect of the Loess Plateau based on the precipitation gradient and land use. Results showed that the vertical profiles of soil moisture revealed large variations with the precipitation gradient changing, especially in the surface layer $(0-100 \mathrm{~cm})$. Significant linear correlation existed between the average soil moisture of the profile and the mean annual precipitation (MAP) for each land use type $(p<0 \cdot 05)$. Hereinto, the soil moisture under the grassland was affected more greatly by precipitation. The soil moisture under each land use commonly revealed the trend as farmland $>$ grassland $>$ shrubland $>$ woodland, while it might be higher under the woodland than the shrubland in the surface layer in regions with MAP $<500 \mathrm{~mm}$. The soil moisture of woodland or shrubland at the selected points was below or approximate to the permanent wilting point in regions with MAP $<520 \mathrm{~mm}$. Covariance analysis confirmed the effects of land use and MAP on the soil moisture in depth of 100-300 cm, and it showed land use did not pose significant effects in the surface layer. In addition, our study indicated that it is necessary to reconsider and re-evaluate the current vegetation restoration strategy in the perspective of vegetation sustainability and soil water availability, in which woodland and shrubland were selected on a large scale in the arid and semi-arid regions. Copyright (C) 2016 John Wiley \& Sons, Ltd.
\end{abstract}

KEY WORDS: $\quad$ soil moisture; land use type; precipitation gradient; restoration strategy; north-south transect

\section{INTRODUCTION}

Anthropogenic activities have induced land degradation processes, which further affect the atmosphere, water resources, biota and soils (Berendse et al., 2015; Bochet, 2015; Gao et al., 2015; Muñoz-Rojas et al., 2015; Parras-Alcántara et al., 2015; Qadir et al., 2013). These impacts would affect the hydrological cycle and lead to distinct spatio-temporal variability of the hydrological regimes, especially in waterlimited regions (Cohen et al., 2014; Gao et al., 2015; Milly et al., 2005). Soil moisture is an integrative state variable that plays key roles in many terrestrial ecosystem processes especially in arid and semi-arid environments (Legates et al., 2011; Porporato et al., 2002; Yang et al., 2014a). The spatio-temporal variability of soil moisture regulates many hydrological processes (Famiglietti et al., 1998). Characterizing soil moisture variations across a range of spatial and temporal scales is fundamental to understand and model eco-hydrological processes because of the complex and nonlinear relationships among various biophysical processes and soil moisture (Famiglietti et al., 1998; Yang et al., 2015). Exploring the soil moisture variation at

*Correspondence to: B. Fu, State Key Laboratory of Urban and Regional Ecology, Research Center for Eco-Environmental Sciences, Chinese Academy of Sciences, PO Box 2871, Beijing 100085, PR China.

E-mail: bfu@ @rcees.ac.cn regional scale is a key issue for the eco-hydrology research in water-limited regions such as the Loess Plateau in China.

The Loess Plateau is located in the middle reaches of the Yellow River basin in China with a total area of 0.64 million $\mathrm{km}^{2}$ (Feng et al., 2012). The natural vegetation cover in the Loess Plateau is generally low, and the cultivated croplands are the main land use type due to the long history of human settlement (Feng et al., 2012). The loose loess soils, steep slopes, high rainfall intensity and poor vegetation conditions have made the Loess Plateau one of the most severely eroded areas in the world (Gao et al., 2015; Li et al., 2009). Several efforts including afforestation, pasture reestablishment, terraces and check dams have been made to control soil erosion and restore ecological functions (Liang et al., 2015). The Grain for Green project aiming to convert steep cropland to forest and pasture lands have been implemented at the end of the 1990s (Feng et al., 2012).

The land use has changed dramatically with the implementation of Grain for Green project in the Loess Plateau, which altered the hydrological cycle. For example, the soil water repellency would be affected by land use change, which further triggers soil and water loess (Keesstra et al., 2016). The soil moisture variation research has drawn considerate attentions in this region. The soil moisture patterns of different vegetation types in the catchments of the Loess Plateau have been well studied in recent studies (Wang et al., 2013a). The soil moisture 
difference between different land use/vegetation has been compared in many catchments in the Loess Plateau (e.g. Chen et al., 2004; Qiu et al., 2001), and such studies indicated that soil moisture in bare soils were usually higher than that in vegetated soils, and soil moisture in annual crops and grasses was higher than that in forests (Wang et al., 2013a). The water balance in the soil-vegetation-atmosphere system was also studied in the catchments, indicating that the vegetation type would be a major influencing factor (Wang et al., 2011a).

There are limited regional-scale studies on the soil moisture spatio-temporal variability in the Loess Plateau. Entin et al. (2000) found that the soil moisture variance at small scale was controlled by soil, topography, vegetation and root structure, and at large scale it was controlled by the atmosphere. Vinnikov et al. (1996) indicated that the spatial variability in the red noise component of soil moisture reflects the statistical properties of the monthly averaged precipitation field at the scale of about $500 \mathrm{~km}$. Wang \& Franz (2015) examined the effect of soil hydraulic parameters on soil moisture spatial variability and found that the mean relative difference of soil moisture was mainly controlled by soil hydraulic properties instead of the climatic factors. The dominant factors of soil moisture spatial variability at regional scale still need further analysis in the Loess Plateau. In addition, soil properties and hydrological processes revealed corresponding variations along the environmental gradient (altitudinal gradient, climatological gradient and recuperation gradient), while the variations might also be linked to many factors such as land use (Campos et al., 2014; Cerdà, 1998a; Cerdà, 1998b; Choudhury et al., 2015; Hedo et al., 2015; Vasconcellos et al., 2016). The precipitation gradient factor would affect the role played by the soil surface component in regulating soil hydrological processes (Ruiz Sinoga et al., 2010). In the Loess Plateau, precipitation gradient exists ranging from $750 \mathrm{~mm}$ in the southeast to $200 \mathrm{~mm}$ in the northeast, which provides excellent opportunities to study the soil moisture variation in the whole matrix and incorporates variation caused by land use. Thus, it is necessary to study the soil moisture variation with land use along the precipitation gradient in the Loess Plateau.

In this study, we characterized the soil moisture variations with the environmental gradient in the north-south transect of the Loess Plateau. Specifically, the objectives are (i) to characterize soil moisture variations with the land use type and precipitation gradient across the north-south transect of the Loess Plateau and (ii) to explore the effects of land use and precipitation on the soil moisture at different layers.

\section{MATERIAL AND METHODS}

\section{Study Areas and Sites}

The Loess Plateau is located between $102-114^{\circ} \mathrm{E}$ and $35-$ $41^{\circ} \mathrm{N}$ (Figure 1). Following the precipitation gradient, the vegetation distribution pattern varies from forests in the south to grasslands in the north (Feng et al., 2012).
The north-south transect of the Loess Plateau was selected based on the precipitation gradient. The transect included all the main regional climate conditions and vegetation types. A total of 11 sites were chosen to characterize the spatial variation of soil moisture (Table I). The landform at these sites is typical loess and hilly, and the mean annual precipitation (MAP) increases from $406 \mathrm{~mm}$ at the northern site to $624 \mathrm{~mm}$ at the southern site.

\section{Soil Sampling and Measurement Method}

In July and August of 2014, a total of 45 sampling points were chosen at the 11 sites based on land use type (Table I). The land use types selected in this study are woodland, shrubland, grassland and farmland. It is noted that the farmlands selected had undergone similar cultivation practices (i.e. no irrigation and normal fertilization levels). No precipitation occurred during the sampling periods at each site or a week before sampling. Soil samples in depth of $0-300 \mathrm{~cm}$ were taken by an auger $(5 \mathrm{~cm}$ in diameter) with $20 \mathrm{~cm}$ interval. The soil samples were kept immediately in airtight aluminium boxes after they were taken out. The gravimetrically soil moisture content was measured using the oven-dry method $\left(24 \mathrm{~h}\right.$ at $\left.105^{\circ} \mathrm{C}\right)$ in the laboratory. The volumetric soil moisture content was calculated by multiplying the gravimetric water content and the bulk density and dropping the units. In the majority of the sampling points, soils were collected along a vertical profile over $300 \mathrm{~cm}$ except for a few exceptions at the northern site. The latitude, longitude and elevation were determined for each sampling point by a handheld global positioning system device Magellan 500. The slope gradient and aspects were determined by a compass in field investigations. The undisturbed soil cores were collected at each sampling point to obtain the soil bulk density with metal cylinders $(5 \mathrm{~cm}$ in diameter and $5 \mathrm{~cm}$ in length) and to determine field capacity and permanent wilting point by the capillary suction method.

\section{Data and Statistical Analysis}

The $K$ value was introduced to describe the variation trend of soil moisture vertical profiles, which is the linear regression coefficient between soil moisture and soil depth (Wang et al., 2014). A positive $K$ value means the soil moisture would increase with soil depth and vice versa. Paired sample $t$-test was used to examine the effect of topography factors (slope position, slope gradient and slope aspect) on soil moisture variation at regional scale. In this study, the sampling points were divided into three groups to analyse the soil moisture variation under the effects of terrain factors. To elucidate the role of slope aspect on the soil moisture, several pairs of points were selected to compare soil moisture affected by slope aspect. It is noted that each pair of sites under the same land use type selected in this group was on similar slope position, similar slope gradient and similar precipitation conditions, but varied by slope aspects. The other two 


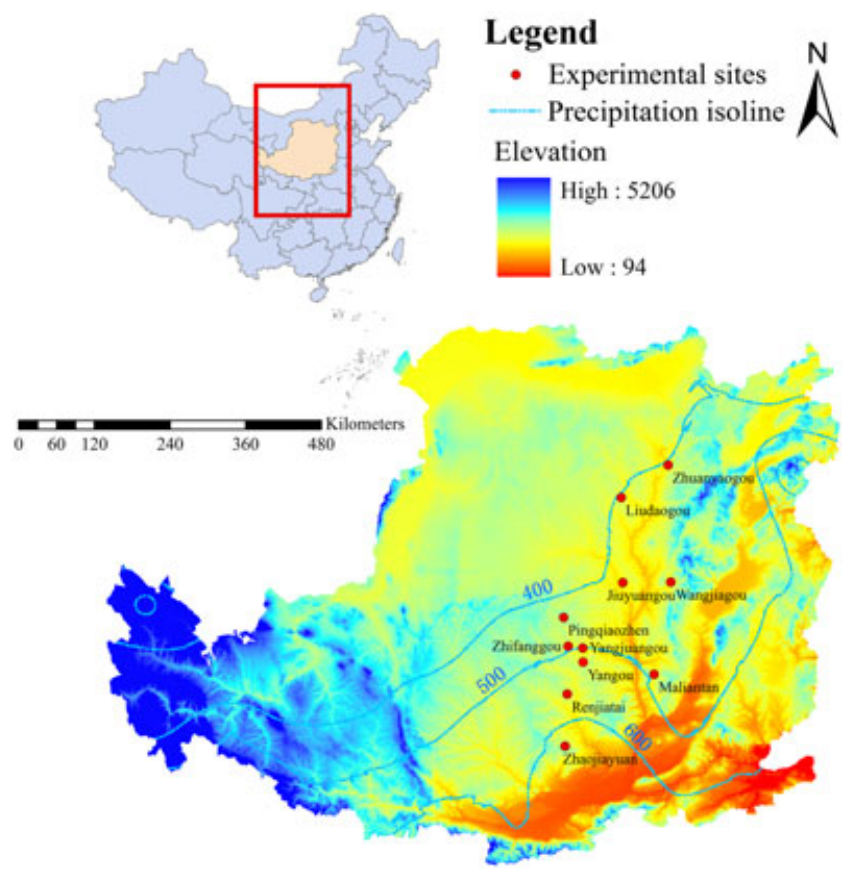

Figure 1. Location of sampling sites in the catchments across the Loess Plateau. [Colour figure can be viewed at wileyonlinelibrary.com]

groups of sampling points were also selected to analyse the role of slope position and slope gradient on the soil moisture according to the criteria earlier (Table S1). Covariance analysis was used to explore the effects of precipitation and land use on the soil moisture at regional scale.

\section{RESULTS}

\section{General Features of Profile Distribution of the Soil Moisture}

The vertical profiles $(0-300 \mathrm{~cm})$ of soil moisture at 45 sampling points were shown in Figure 2. The soil moisture of the vertical profiles reveals great variability in the 0 - to $100-\mathrm{cm}$ soil layer. The range of soil moisture of vertical profiles varied greatly with the precipitation. Generally, the soil moisture under woodland and shrubland was lower than that in the farmland and grassland, especially in the deep layers, despite the environmental gradient differences across the transect. The vertical profiles of soil moisture variations at these sites revealed different trends, for example, the soil moisture in sampling points $(30,31,32,33$ and 34) in Yangjuangou catchment revealed a consistent increasing trend, while the soil moisture in sampling points $(20,21$, 22, 23 and 24) in Maliantan catchment revealed a consistent decreasing trend. The $K$ values along the vertical soil profiles in these points ranged from -0.00036 to 0.00037 (Figure 3 a). The points with $K$ values lower than -0.0015 showed an obvious decreasing trend, and these points belong to woodland/shrubland located in regions where MAP ranges from 475 to $575 \mathrm{~mm}$. The points with $K$ values larger than 0.0015 showed an obvious increasing trend, and these points mostly belong to farmland/grassland located in regions where MAP $>550$ or $<450 \mathrm{~mm}$. The average soil moisture of the vertical profiles $(0-300 \mathrm{~cm})$ under different land use types was shown in Figure 3b. Results showed the order of average soil moisture under the four land use types was farmland $(15 \cdot 23 \%)>$ grassland $(12 \cdot 34 \%)>$ shrubland $(10.43 \%)$ $>$ woodland $(10.41 \%)$, and the woodland revealed greatest variability, while the farmland revealed smallest variability.

\section{The Soil Moisture Variations with Environmental Gradient}

The relationships between the soil moisture and MAP under each land use type were shown in Figure 4. There was a significant linear correlation between the soil moisture and MAP for each land use in different layers, except for the farmland in 0 - to $100-\mathrm{cm}$ and $100-$ to $200-\mathrm{cm}$ layer $(p>0 \cdot 05)$. Results showed that the correlation coefficient in different layers varied from 0.56 to 0.87 , which was highest for grassland in 100-200 cm and lowest for farmland in $0-100 \mathrm{~cm}$. The linear correlation between soil moisture and MAP indicated that the soil moisture under each land

Table I. General information of 45 sampling points across the north-south transect in the Loess Plateau

\begin{tabular}{lll}
\hline Category & & \multicolumn{1}{c}{ Sampling points } \\
\hline Land use type & Woodland $(n=18)$ & $1,7,8,9,13,16,20,21,23,25,27,29,30,37,38,40,42,43$ \\
& Shrubland $(n=10)$ & $4,10,14,17,22,26,28,34,35,39$ \\
& Grassland $(n=10)$ & $2,5,11,12,15,18,31,32,36,45$ \\
Fite & Farmland $(n=7)$ & $3,6,19,24,33,41,44$ \\
& Zhuanyaogou catchment $(n=4)$, MAP $=406 \mathrm{~mm}$ & $1,2,3,4$ \\
& Jiuyuangou catchment $(n=4), \mathrm{MAP}=415 \mathrm{~mm}$ & $5,6,7,8$ \\
& Liudaogou catchment $(n=5), \mathrm{MAP}=430 \mathrm{~mm}$ & $9,10,11,12,13$ \\
& Pingqiaozhen $(n=3), \mathrm{MAP}=436 \mathrm{~mm}$ & $14,15,16$ \\
& Wangjiagou catchment $(n=3), \mathrm{MAP}=460 \mathrm{~mm}$ & $17,18,19$ \\
& Maliantan $(n=5)$, MAP $=488 \mathrm{~mm}$ & $20,21,22,23,24$ \\
& Yangou catchment $(n=5), \mathrm{MAP}=520 \mathrm{~mm}$ & $25,26,27,28,29$ \\
& Yangjuangou catchment $(n=5), \mathrm{MAP}=535 \mathrm{~mm}$ & $30,31,32,33,34$ \\
& Zhifanggou catchment $(n=3), \mathrm{MAP}=550 \mathrm{~mm}$ & $35,36,37$ \\
& Renjiatai $(n=4)$, MAP $=560 \mathrm{~mm}$ & $38,39,40,41$ \\
& Zhaojiayuan $(n=4)$, MAP $=624 \mathrm{~mm}$ & $42,43,44,45$ \\
\hline
\end{tabular}

MAP, mean annual precipitation. 


\section{Soil moisture (\%)}

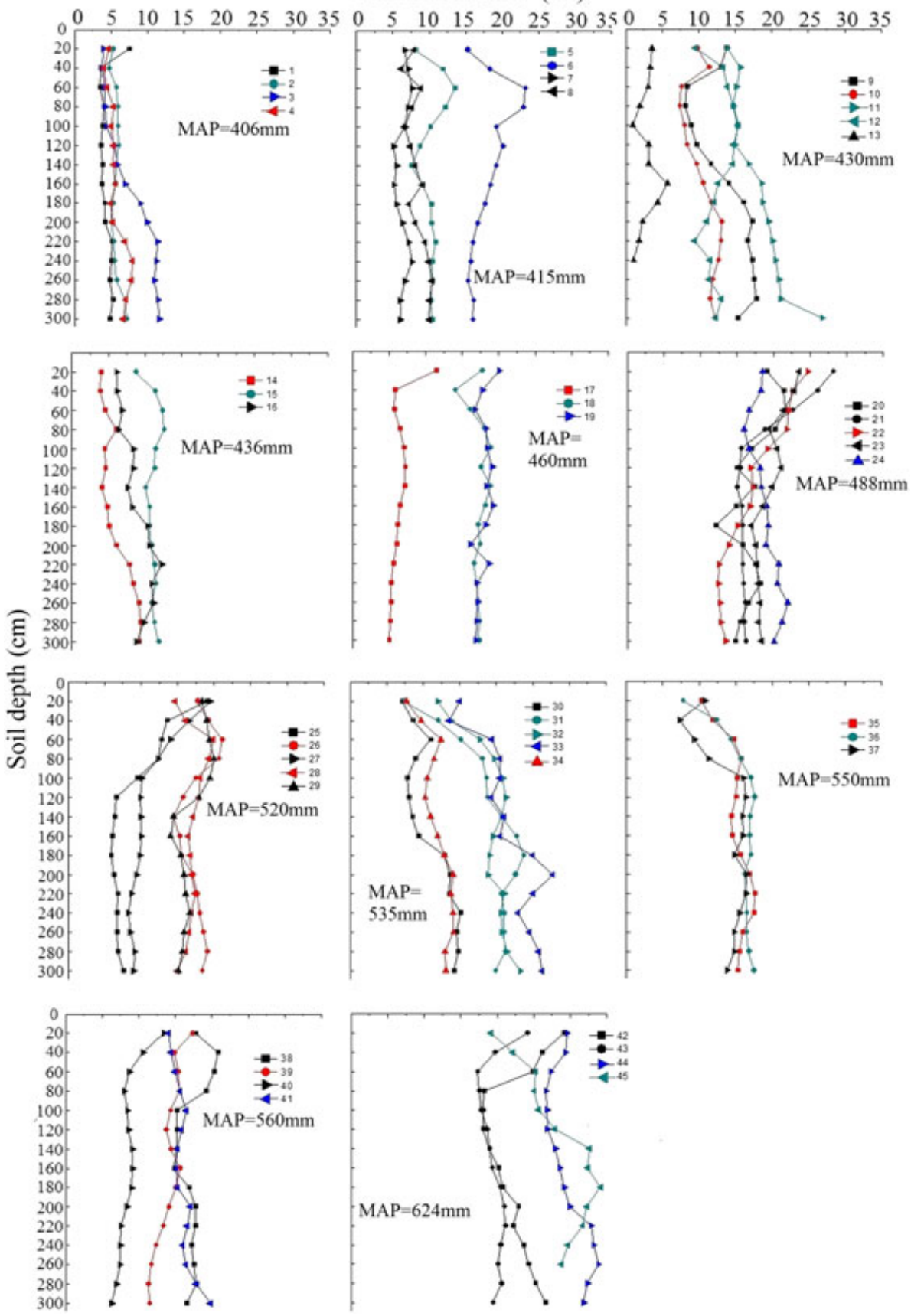

Figure 2. Vertical profiles of soil moisture at 45 sampling points (black points represent the woodland, red points represent the shrubland, green points represent the grassland and blue points represent the farmland). MAP, mean annual precipitation. [Colour figure can be viewed at wileyonlinelibrary.com]

use type varied with the MAP gradient. The slope of regression equation between soil moisture and MAP indicated how the soil moisture varied with the precipitation gradient. The soil moisture under shrubland in $0-100 \mathrm{~cm}$ increased most with MAP increasing, and the grassland increased most with MAP increasing in 100-200 and $200-300 \mathrm{~cm}$ compared with other land use types. In addition, the average soil moisture also revealed significant linear correlation with MAP for each land use type $(p<0.01$ for woodland and grassland; $p<0.05$ for shrubland and grassland).
The comparisons among soil moisture at each site were shown in Figure 5. Results showed that the soil moisture in the surface layer $(0-100 \mathrm{~cm})$ under each land use types along the precipitation gradient did not reveal a consistent trend. In the middle layer $(100-200 \mathrm{~cm})$ and deep layer $(200-300 \mathrm{~cm})$, the soil moisture under each land use type basically revealed the common trend as farmland $>$ grassland $>$ shrubland $>$ woodland. The soil field capacity and permanent wilting point were compared with the soil moisture at the sites along the precipitation (Figure 5). 

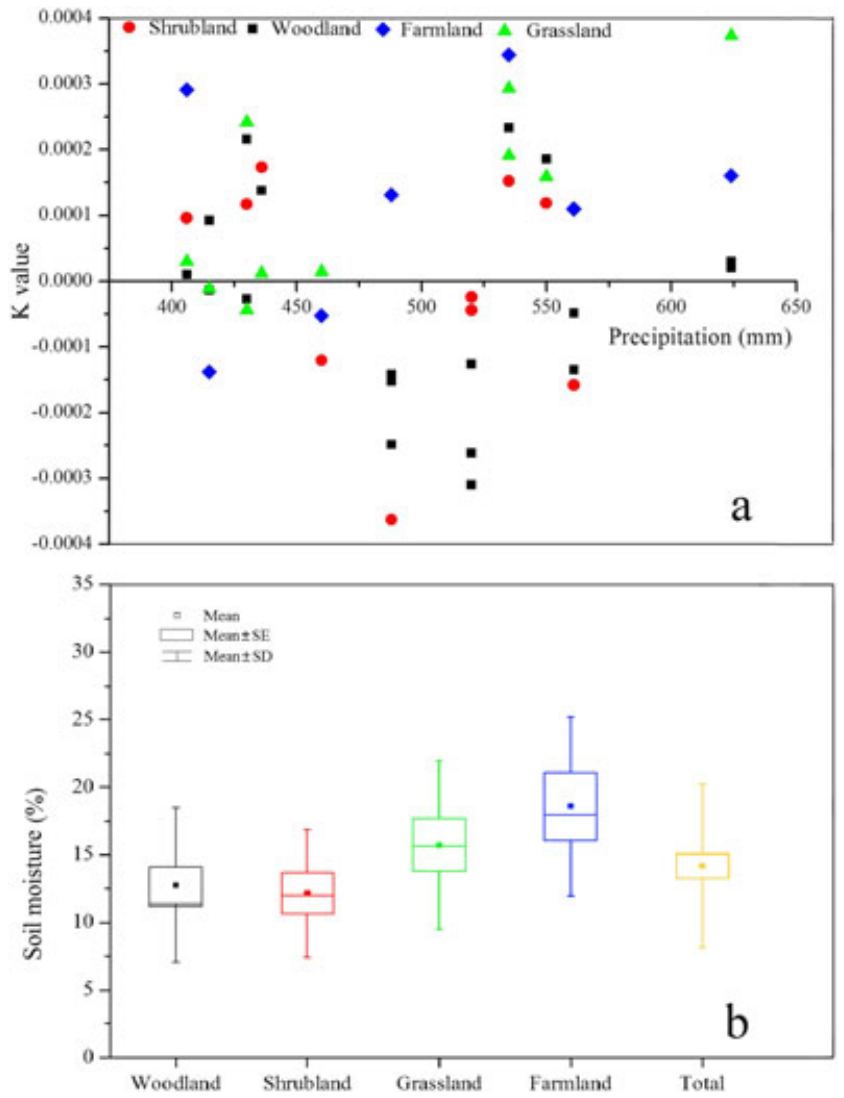

Figure 3. Statistical parameters of soil moisture content at 45 sampling points in the catchments across the Loess Plateau. [Colour figure can be viewed at wileyonlinelibrary.com]

Results showed that the soil moisture monitored in this study mostly ranged from the permanent wilting point to field capacity across the transect, while some exceeded this range. In the surface layer $(0-100 \mathrm{~cm})$, the soil moisture of shrubland and woodland was approximate to or below the permanent wilting point at the sites with MAP $<480 \mathrm{~mm}$. In the middle layer $(100-200 \mathrm{~cm})$ and deep layer $(200-$ $300 \mathrm{~cm}$ ), the soil moisture of shrubland and woodland was approximate to or below the permanent wilting point at the sites with MAP $<520 \mathrm{~mm}$.

\section{Effects of Land Use and Precipitation on Soil Moisture Content}

In order to illuminate the effects of land use and precipitation on the soil moisture across the transect, the effects of terrain factors were first examined. The sampling points were divided into three groups to examine the effects of slope aspect, slope degree and slope positions on the soil moisture, respectively (Table S1). The paired sample $t$-test results showed there were no significant differences in soil moisture in each layer between shady and sunny lands, between steep and gentle slopes, and between higher and lower slope positions, respectively. These results indicated the slope aspect, slope degree and slope positions did not play a significant role on the soil moisture at selected sites across the transect.
Thus, the effects of land use and precipitation were examined through analysis of covariance (Table II). Results revealed that in the surface layer $(0-100 \mathrm{~cm})$ the MAP had significant effects on the soil moisture $(p<0.01)$, while land use did not reveal significant effects, which might be explained that various factors affect the surface soil moisture and they revealed large spatio-temporal variability. In the middle layer $(100-200 \mathrm{~cm})$ and deep layer $(200-300 \mathrm{~cm})$, both the MAP and land use had significant effects on the soil moisture $(p<0 \cdot 01)$.

\section{DISCUSSION}

\section{Vertical Features of Soil Moisture along the Transect}

In this study, the vertical profiles of soil moisture variations in Yangjuangou catchment $(\mathrm{MAP}=535 \mathrm{~mm})$ revealed a consistent increasing trend, while those in Maliantan catchment ( $\mathrm{MAP}=488 \mathrm{~mm}$ ) revealed a consistent decreasing trend, despite the order of soil moisture under each land use type remains consistent. The soil moisture under Caragana korshinskii was also found to decrease with the soil depth in the 470- to 500-mm precipitation zone (Liu et al., 2016). This could be explained that some other factors might play important roles, although the land use still affects the vertical profiles of soil moisture. Previous studies have indicated that the vertical profiles of soil moisture might decrease with the vegetation growth (Wang, 2010). The growth age of the introduced vegetation in Yangjuangou catchment was no more than 15 years, which is shorter than that in Maliantan catchment (about 20-30 years). In addition, it might also be related to the rooting depth and distribution in the two sites. Wang et al. (2010b) found that significant correlation relationships between root indices and soil moisture within the profiles, and the root indices varied with vegetation type and ages of vegetation. The soil moisture profiles in the surface layer revealed greater variations compared with deep layers, which was also consistent with recent study on the spatial variations of soil moisture under C. korshinskii (Liu et al., 2016). A number of factors could contribute to the large variability in the profile of soil moisture in the surface layer, including surface evaporation, transpiration from shallow-rooted vegetation and the precipitation recharge. Soil evaporation from soil is generally constrained to the surface soil layer (Suleiman \& Ritchie, 2003) and is affected by canopy cover and soil temperature differences because of the vegetation cover changing. Another key effect of vegetation on surface soil moisture is transpiration from the soil profile (Western et al., 1999), as the fine root systems of introduced vegetation in the Loess Plateau were mainly distributed in shallow layers (Yang et al., 2014b), while the root system distribution pattern in the surface layer varied with the vegetation types. Land cover changes would also affect the water recharge to soil and surface water (Wang et al., 2011a). These mentioned factors contribute to the large variability of the soil moisture profiles in the surface layer. The smaller variations in deep layer soil moisture might be more affected by the land use. Dynamic monitoring and soil sampling in the 

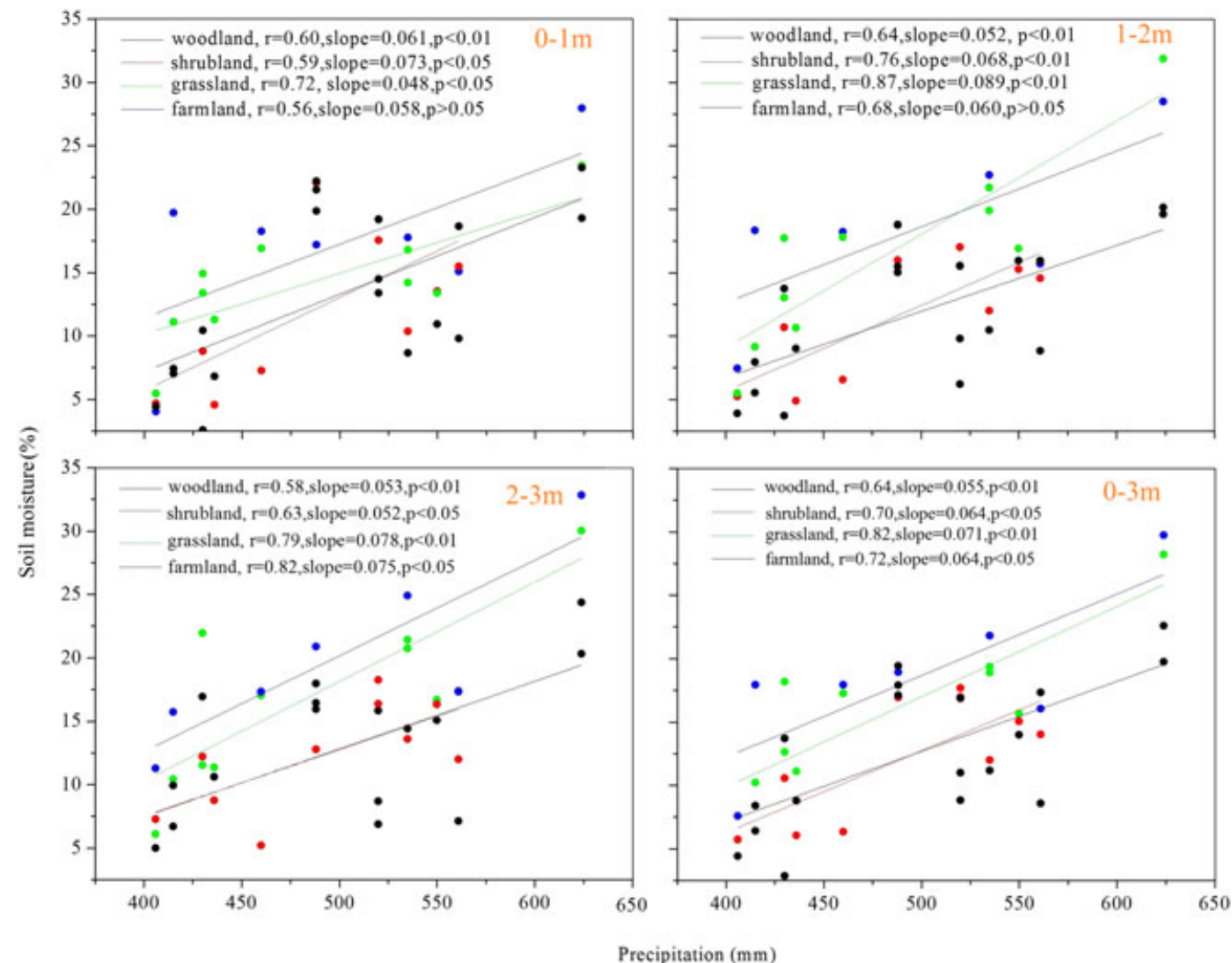

Figure 4. The soil moisture variation with the precipitation gradient at different depths under each land use type. [Colour figure can be viewed at wileyonlinelibrary.com]

catchments have proved that the soil moisture in the layer below $100 \mathrm{~cm}$ was not affected by the frequent light rains in the Loess Plateau (Yang et al., 2012). The underground water also did not affect the soil moisture because of the deep loess soil. The soil moisture is temporally stable in the deep layer, and the variations in the deep soil layer were mainly caused by the land cover types changing with different water consumptions. The introduced vegetation has deep roots, for example, the roots of $C$. korshinskii, which could reach $640 \mathrm{~cm}$ (Wang et al., 2010b), while the rain infiltration depth was found to be $200 \mathrm{~cm}$ in the drought year and $300 \mathrm{~cm}$ in the rainy year (Chen et al., 2008). Thus, effects of precipitation on the deep layer soil moisture were secondary compared with the land use, especially in the lowest layer (2-3 m). The $K$ value was introduced to reflect the vertical variations of the soil moisture in each sampling points; the results showed that the grassland or farmland located in the relatively humid and arid regions would probably reveal increasing trends, while the woodland or shrubland located in transition zones between these regions mentioned earlier would probably reveal decreasing trends. The grassland and farmland mainly consume the soil moisture in the surface layer because of their root systems, even in the relatively arid regions. It is reasonable that woodland and shrubland would probably reveal decreasing trends because of their deep root systems. Why the woodland or shrubland did not reveal obvious decreasing trends in the relatively arid regions? In the relatively arid regions, the soil moisture content from surface to deep layers was low and has limited water for vegetation absorption. Meanwhile, the soil evaporation in the arid areas posed obvious effects on the surface soil moisture. Thus, the deep soil moisture might be higher than the surface soil moisture. In addition, the root distribution would also influence the soil moisture trend in the profile, as significant correlation relationships exist between root indices and soil moisture within the profiles (Wang et al., 2010b).

\section{Controls of Land Use and Precipitation on Soil Moisture at} Regional Scale

Significant linear correlation existed between soil moisture of the profile and the MAP for each land use type, which indicated that the soil moisture under different land use types varied with the precipitation gradient in varying degrees. Analysis of covariance confirmed the significant effects of land use and MAP on the soil moisture across the transect, while the land use did not pose significant effects on the soil moisture in the surface layer. Soil moisture in the surface layer was affected by various factors, including rainfall infiltration, evapotranspiration, land cover, topographic features and soil properties (Ferreira et al., 2007; Qiu et al., 2001; Western et al., 1999). In addition, these factors revealed large spatio-temporal variability across the transect in the Loess Plateau. The effects of these factors on the soil moisture would decrease with the soil profile, while the soil 


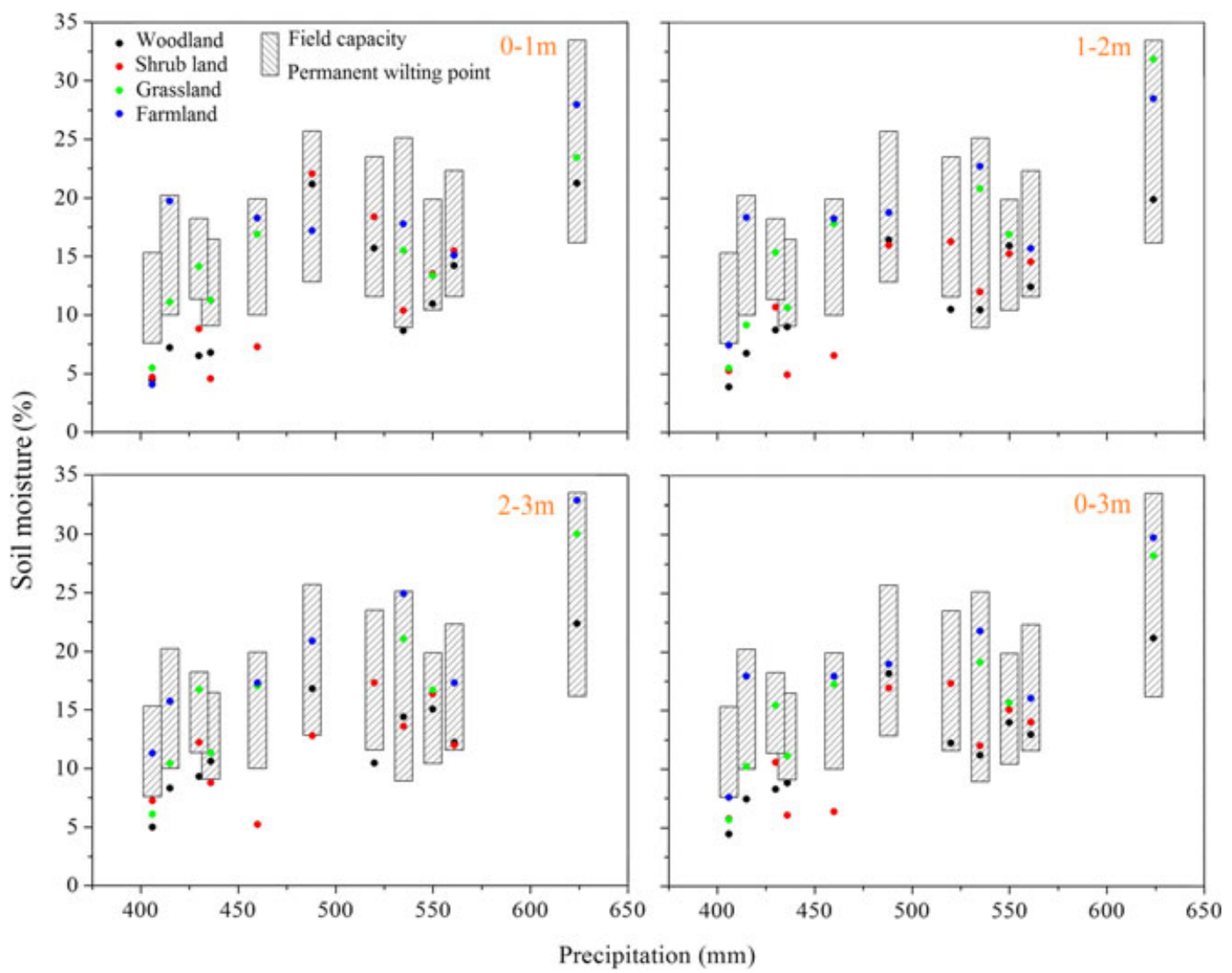

Figure 5. Comparisons of soil moisture under each land use type at each site along the precipitation gradient. [Colour figure can be viewed at wileyonlinelibrary.com]

moisture in the deep layer was more affected by land use because of the root systems. Thus, the effects of land use on the surface soil moisture were not significant compared with the deep layer. On the other hand, the unsaturated soil layer is deep and groundwater is located at a depth of 50-200 m below the soil surface in the Loess Plateau (Chen et al., 2008). Rainfall infiltration is the only source of water for the soil in the Loess Plateau, and the recharge depth by the precipitation was in the 0 - to $100-\mathrm{cm}$ depth (Yang et al., 2014a). The precipitation varied greatly across the transect in the Loess Plateau at large scale; it is reasonable that the effects of precipitation on the surface soil moisture were dominant. It is noted that the precipitation effects on surface

Table II. Summary of analysis of covariance results for the soil moisture in each layer in relation to MAP and land use type

\begin{tabular}{lccc}
\hline $\begin{array}{l}\text { Source of } \\
\text { variations }\end{array}$ & $\begin{array}{c}\text { Soil moisture } \\
(0-100 \mathrm{~cm})\end{array}$ & $\begin{array}{c}\text { Soil moisture } \\
(100-200 \mathrm{~cm})\end{array}$ & $\begin{array}{r}\text { Soil moisture } \\
(200-300 \mathrm{~cm})\end{array}$ \\
\hline MAP & $<0.001$ & $<0.001$ & $<0.001$ \\
Land use & 0.86 & $<0.001$ & $<0.001$ \\
MAP $\times$ land & 0.924 & 0.43 & 0.691 \\
use & & & \\
\hline
\end{tabular}

MAP, mean annual precipitation. soil moisture were dominant at large scale, while land use effects were still dominant at small scale. The effects of land use on the soil moisture in the deep layers have been proved in previous studies in small catchments on the Loess Plateau (Zeng et al., 2011; Zhang et al., 2012). Land use also had a direct effect on the hydrological processes despite the strong influences of climate (Campos et al., 2014; Cerdà, 1998a; Cerdà, 1998b; Choudhury et al., 2015; Vasconcellos et al., 2016). Root water uptake was as an important process controlling soil moisture dynamic in the Loess Plateau (Yang et al., 2014a). The woodland and shrubland sampling points selected in this study were mainly covered by introduced vegetation with root systems mainly distributed in shallow layers; however, all types of introduced vegetation have deep root systems below the precipitation infiltration depth and could consume more deep soil moisture than farmland and grassland (Chen et al., 2010; Yang et al., 2014b). The root system of maize crop in the farmland could only reach approximately $100 \mathrm{~cm}$, which is shallower than that in grassland and woodland (Wang \& Jiao, 2011). Wang et al. (2010b) found that the roots of soybean and Stipa bubgeana were mainly distributed in the $0-100 \mathrm{~cm}$ and the roots of $C$. korshinskii could extend to $640 \mathrm{~cm}$. Wang et al. (2011b) found that the formation depth of dried soil layer under the Robinia pseudoscacia was at $100 \mathrm{~cm}$ below the soil surface and its thickness was $491 \mathrm{~cm}$, and the formation depth of 
dried soil layer under the C. korshinskii was at $162 \mathrm{~cm}$ below the soil surface and its thickness was $294 \mathrm{~cm}$, which also indicted a larger impacts at deeper layer exerted by the introduced vegetation. The excessive depletion of soil water by the deep root system without sufficient precipitation infiltration results in the lower level of deep soil moisture under the woodland and shrubland (Yang et al., 2014a). The amount of precipitation infiltrating is distinct under different land use types because of the crown interception; the amount of precipitation infiltrating woodland is lower than the amount infiltrating shrubland, artificial grassland (Yu et al., 2015). In addition, the difference in leaf area index in different land use types would also cause the difference in soil water consumption (Wang et al., 2013b). The precipitation and land use affect the source and consumption of the soil moisture, which further affect the soil moisture variability.

\section{Implications for the Restoration Strategy}

The large-scale vegetation restoration projects were implemented in the Loess Plateau to control soil and water loss, while their dire challenges remain to be confronted. No guidance for plant species selection for the restoration purpose virtually existed (Chen et al., 2010). Our results showed that the middle and deep layer soil moisture of shrubland/woodland was approximate to or below the permanent wilting point at the sites with MAP $<520 \mathrm{~mm}$, which further indicated that the restoration approaches might exacerbate soil moisture deficits and result in serious soil desiccation, and a reduction in vegetation carrying capacity (Wang et al., 2010b). Although the soil moisture could be replenished by rainfall during rainy season, the effective influence depth of light rainfalls on soil moisture did not exceed $60 \mathrm{~cm}$ (Li et al., 2006), the soil moisture below $100 \mathrm{~cm}$ has been proved fairly stable in case of no heavy or continuous rains (Li et al., 2006; Wang et al., 2010a) and the soil moisture below $200 \mathrm{~cm}$ might be unchanged for many years in the Loess Plateau (Wang et al., 2009; Yao et al., 2012). Then, we might speculate that the soil moisture below $200 \mathrm{~cm}$ could hardly be replenished by rainfall during rainy seasons in the Loess Plateau. Thus, we could conclude that the soil moisture of deep layer (200$300 \mathrm{~cm}$ ) under woodland/shrubland below or approximate to the permanent wilting point is non-sustainable with regard to soil water availability, and it is necessary to reconsider the selection of restoration vegetation cover type in the restoration project. In the perspective of vegetation sustainability and soil water availability, our results indicate that the large-scale woodland/shrubland might not be the optimal solution to the vegetation restoration in the regions with MAP $<520 \mathrm{~mm}$ in the Loess Plateau, and drastic measures should be taken to monitor and retain soil moisture. The precipitation gradient played significant roles in the ecogeomorphological processes (Ruiz Sinoga et al., 2010), and vegetation cover and type are associated with the precipitation gradient. Through soil-vegetation interaction, vegetation affects the infiltration rates and water holding capacity (Ruiz Sinoga et al., 2010); thus, soil moisture under different vegetation types would reveal great variations along the profile. In this study, the incidence of the precipitation gradient threshold was detected at MAP $=520 \mathrm{~mm}$ for woodland/shrubland. Related studies found that dwarfed trees have occurred throughout the reforestation regions with MAP $<400 \mathrm{~mm}$ in the Loess Plateau (Cao et al., 2011; McVicar et al., 2010), which also confirmed the negative effects in the large-scale afforestation. Vegetation restoration is a complex issue, relating to many aspects, especially in the Loess Plateau. Actually, many studies have focused on the unintended environmental, ecological and socio-economic consequences in the current vegetation restoration (Cao et al., 2011; Hu \& Shao, 2002), and our results at least lead to the refection on the current vegetation restoration. The policy should convert from forest-shrub-based approach to evidence-based approach (Cao et al., 2011). Further study should focus on the influence of spatial patterns of land use types and long-term vegetation restoration on soil moisture dynamics.

\section{CONCLUSIONS}

The vertical profiles of soil moisture across the transect revealed large variations, especially in the surface layer (0$100 \mathrm{~cm}$ ). There was significant linear correlation between the soil moisture and MAP for each land use type, and the soil moisture under the grassland was affected more greatly by the precipitation compared with other land use types. The soil moisture under each land use type generally revealed the common trend as farmland $>$ grassland $>$ shrubland $>$ woodland, while the soil moisture in the surface layer did not reveal this consistent trend. In addition, the soil moisture of shrubland and woodland at the selected sites was approximate to or below the permanent wilting point in regions with MAP $<520 \mathrm{~mm}$. The effects of MAP and land use on the soil moisture across the transect were confirmed by the analysis of covariance $(p<0 \cdot 01)$, while the land use posed no significant effects on the soil moisture in the surface layer. The results provided new information and held implications for the restoration that the woodland/shrubland is non-sustainable with regard to soil water availability and might not be the optimal solution to the current vegetation restoration in the arid and semiarid regions in the Loess Plateau. Understanding the soil moisture variation characteristics under different land use types along the precipitation gradient in individual layers would help with the sustainable land use and water management in the Loess Plateau.

\section{ACKNOWLEDGEMENT}

This work was funded by the National Natural Science Foundation of China (nos. 41390464, 41401027 and 41501284). 


\section{REFERENCES}

Berendse F, van Ruijven J, Jongejans E, Keesstra S. 2015. Loss of plant species diversity reduces soil erosion resistance. Ecosystems 18: 881-888. DOI:10.1007/s10021-015-9869-6.

Bochet E. 2015. The fate of seeds in the soil: a review of the influence of overland flow on seed removal and its consequences for the vegetation of arid and semiarid patchy ecosystems. Soil 1: 131-146. DOI:10.5194/ soil-1-131-2015.

Campos A, Etchevers J, Oleschko K, Hidalgo C. 2014. Soil microbial biomass and nitrogen mineralization rates along an altitudinal gradient on the Cofre de Perote Volcano (Mexico): the importance of landscape position and land use. Land Degradation \& Development 25: 581-593. DOI:10.1002/ldr.2185.

Cao S, Sun G, Zhang Z, Chen L, Feng Q, Fu B, McNulty S, Shankman D, Tang J, Wang Y. 2011. Greening China naturally. Ambio 40: 828-831. DOI:10.1007/s13280-011-0150-8.

Cerdà A. 1998a. Effect of climate on surface flow along a climatological gradient in Israel: a field rainfall simulation approach. Journal of Arid Environments 38: 145-159. DOI:10.1006/jare.1997.0342.

Cerdà A. 1998b. Relationships between climate and soil hydrological and erosional characteristics along climatic gradients in Mediterranean limestone areas. Geomorphology 25: 123-134. DOI:10.1016/S0169-555X (98)00033-6.

Chen H, Shao M, Li Y. 2008. The characteristics of soil water cycle and water balance on steep grassland under natural and simulated rainfall conditions in the Loess Plateau of China. Journal of Hydrology 360: 242-251. DOI:10.1016/j.jhydrol.2008.07.037.

Chen L, Wang J, Wei W, Fu B, Wu D. 2010. Effects of landscape restoration on soil water storage and water use in the Loess Plateau Region, China. Forest Ecology and Management 259: 1291-1298. DOI:10.1016/j.foreco.2009.10.025.

Chen Y, Liu G, Yang Q. 2004. Zonal characteristics of artificial forest effecting soil moisture on Loess Plateau (in Chinese). Journal of Natural Resources 19: 195-200. DOI:10.11849/zrzyxb.2004.02.009.

Choudhury BU, Fiyaz AR, Mohapatra KP, Ngachan S. 2015. Impact of land uses, agrophysical variables and altitudinal gradient on soil organic carbon concentration of North-eastern Himalayan Region of India. Land Degradation \& Development 27: 1163-1174. DOI:10.1002/ldr.2338.

Cohen S, Kettner AJ, Syvitski JP. 2014. Global suspended sediment and water discharge dynamics between 1960 and 2010: continental trends and intra-basin sensitivity. Global and Planetary Change 115: 44-58. DOI:10.1016/j.gloplacha.2014.01.011.

Entin JK, Robock A, Vinnikov KY, Hollinger SE, Liu S, Namkhai A. 2000. Temporal and spatial scales of observed soil moisture variations in the extratropics. Journal of Geophysical Research, [Atmospheres] 105: 11865-11877. DOI:10.1029/2000JD900051

Famiglietti J, Rudnicki J, Rodell M. 1998. Variability in surface moisture content along a hillslope transect: Rattlesnake Hill, Texas. Journal of Hydrology 210: 259-281. DOI:10.1016/S0022-1694(98)00187-5.

Feng XM, Sun G, Fu BJ, Su CH, Liu Y, Lamparski H. 2012. Regional effects of vegetation restoration on water yield across the Loess Plateau, China. Hydrology and Earth System Sciences 16: 2617-2628. DOI:10.5194/hess-16-2617-2012.

Ferreira JN, Bustamante M, Garcia-Montiel DC, Caylor KK, Davidson EA. 2007. Spatial variation in vegetation structure coupled to plant available water determined by two-dimensional soil resistivity profiling in a Brazilian savanna. Oecologia 153: 417-430. DOI:10.1007/s00442-007-0747-6.

Gao G, Ma Y, Fu B. 2015. Temporal variations of flow-sediment relationships in a highly erodible catchment of the Loess Plateau, China. Land Degradation \& Development 27: 758-772. DOI:10.1002/ldr.2455.

Hedo J, Lucas-Borja ME, Wic C, Andrés-Abellán M, de Las Heras J. 2015. Soil microbiological properties and enzymatic activities of longterm post-fire recovery in dry and semiarid Aleppo pine (Pinus halepensis M.) forest stands. Solid Earth 6: 243-252. DOI:10.5194/se6-243-2015.

Hu L, Shao M. 2002. Review on water eco-environment in vegetation restoration in Loess Plateau (in Chinese). Chinese Journal of Applied Ecology 13: 1045-1048. DOI:10.3321/j.issn:1001-9332.2002.08.027.

Keesstra S, Wittenberg L, Maroulis J, Sambalino F, Malkinson D, Cerdà A, Pereira P. 2016. The influence of fire history, plant species and post-fire management on soil water repellency in a Mediterranean catchment: the Mount Carmel range, Israel. Catena. DOI:10.1016/j.catena.2016.04.006.

Legates DR, Mahmood R, Levia DF, DeLiberty TL, Quiring SM, Houser C, Nelson FE. 2011. Soil moisture: a central and unifying theme in physical geography. Progress in Physical Geography 35: 65-86. DOI:10.1177/ 0309133310386514

Li X, Bi H, Li J, Liu X, Guo M. 2006. Dynamics of moisture of soil profile in Loess area of western Shanxi (in Chinese). Science of Soil and Water Conservation 4: 013. DOI:10.3969/j.issn.1672-3007.2006.04.013.

Li Z, Liu W, Zhang X, Zheng F. 2009. Impacts of land use change and climate variability on hydrology in an agricultural catchment on the Loess Plateau of China. Journal of Hydrology 377: 35-42. DOI:10.1016/j. jhydrol.2009.08.007.

Liang W, Bai D, Wang F, Fu B, Yan J, Wang S, Yang Y, Long D, Feng M. 2015. Quantifying the impacts of climate change and ecological restoration on streamflow changes based on a Budyko hydrological model in China's Loess Plateau. Water Resources Research 51: 6500-6519. DOI:10.1002/2014WR016589.

Liu Y, Zhao W, Wang L, Zhang X, Daryanto S, Fang X. 2016. Spatial variations of soil moisture under Caragana korshinskii Kom. from different precipitation zones: field based analysis in the Loess Plateau, China. Forests 7: 31. DOI:10.3390/f7020031.

McVicar TR, Van Niel TG, Li L, Wen Z, Yang Q, Li R, Jiao F. 2010. Parsimoniously modelling perennial vegetation suitability and identifying priority areas to support China's re-vegetation program in the Loess Plateau: matching model complexity to data availability. Forest Ecology and Management 259: 1277-1290. DOI:10.1016/j.foreco.2009.05.002.

Milly PC, Dunne KA, Vecchia AV. 2005. Global pattern of trends in streamflow and water availability in a changing climate. Nature 438: 347-350. DOI:10.1038/nature04312.

Muñoz-Rojas M, Jordán A, Zavala LM, De la Rosa D, Abd-Elmabod SK, Anaya-Romero M. 2015. Impact of land use and land cover changes on organic carbon stocks in Mediterranean soils (1956-2007). Land Degradation \& Development 26: 168-179. DOI:10.1002/ldr.2194.

Parras-Alcántara L, Lozano-García B, Brevik EC, Cerdá A. 2015. Soil organic carbon stocks assessment in Mediterranean natural areas: a comparison of entire soil profiles and soil control sections. Journal of Environmental Management 155: 219-228. DOI:10.1016/j.jenvman.2015.03.039.

Porporato A, D'odorico P, Laio F, Ridolfi L, Rodriguez-Iturbe I. 2002. Ecohydrology of water-controlled ecosystems. Advances in Water Resources 25: 1335-1348. DOI:10.1016/S0309-1708(02)00058-1.

Qadir M, Noble A, Chartres C. 2013. Adapting to climate change by improving water productivity of soils in dry areas. Land Degradation \& Development 24: 12-21. DOI:10.1002/ldr.1091.

Qiu Y, Fu B, Wang J, Chen L. 2001. Soil moisture variation in relation to topography and land use in a hillslope catchment of the Loess Plateau, China. Journal of Hydrology 240: 243-263. DOI:10.1016/S0022-1694 (00)00362-0.

Ruiz Sinoga JD, Garcia Marín R, Martínez-Murillo JF, Gabarrón Galeote MA. 2010. Pluviometric gradient incidence and the hydrological behaviour of soil surface components (southern Spain). Land Degradation \& Development 21: 484-495. DOI:10.1002/ldr.994.

Suleiman A, Ritchie J. 2003. Modeling soil water redistribution during second-stage evaporation. Soil Science Society of America Journal 67: 377-386. DOI:10.2136/sssaj2003.3770.

Vasconcellos RL, Bonfim JA, Baretta D, Cardoso EJ. 2016. Arbuscular mycorrhizal fungi and glomalin-related soil protein as potential indicators of soil quality in a recuperation gradient of the Atlantic forest in Brazil. Land Degradation \& Development 27: 325-334. DOI:10.1002/1dr.2228.

Vinnikov KY, Robock A, Speranskaya NA, Schlosser CA. 1996. Scales of temporal and spatial variability of midlatitude soil moisture. Journal of Geophysical Research 101: 7163-7174. DOI:10.1029/95JD02753.

Wang B, Wen F, Wu J, Wang X, Hu Y. 2014. Vertical profiles of soil water content as influenced by environmental factors in a small catchment on the hilly-gully Loess Plateau. PloS One 9: e109546. DOI:10.1371/journal.pone.0109546.

Wang L, Wei S, Horton R, Ma S. 2011a. Effects of vegetation and slope aspect on water budget in the hill and gully region of the Loess Plateau of China. Catena 87: 90-100. DOI:10.1016/j.catena.2011.05.010.

Wang S, Fu B, Gao G, Liu Y, Zhou J. 2013a. Responses of soil moisture in different land cover types to rainfall events in a re-vegetation catchment area of the Loess Plateau, China. Catena 101: 122-128. DOI:10.1016/j. catena.2012.10.006

Wang T, Franz TE. 2015. Field observations of regional controls of soil hydraulic properties on soil moisture spatial variability in different climate zones. Vadose Zone Journal 14. DOI:10.2136/vzj2015.02.0032.

Wang X, Jiao F. 2011. Partition of soil moisture profiles based on sequential clustering method (in Chinese). Journal of Northwest A \&F University 39: 191-201. 
Wang Y. 2010. Spatial Distribution and Influence Factors of Dried Soil Layers across the Loess Plateau (in Chinese) [D]. Graduate University of Chinese Academy of Sciences.

Wang Y, Ma S, Liu Z. 2010a. Large-scale spatial variability of dried soil layers and related factors across the entire Loess Plateau of China. Geoderma 159: 99-108. DOI:10.1016/j.geoderma.2010.07.001.

Wang Y, Ma S, Liu Z, Horton R. 2013b. Regional-scale variation and distribution patterns of soil saturated hydraulic conductivities in surface and subsurface layers in the loessial soils of China. Journal of Hydrology 487: 13-23. DOI:10.1016/j.jhydrol.2013.02.006.

Wang Y, Ma S, Shao H. 2010b. A preliminary investigation of the dynamic characteristics of dried soil layers on the Loess Plateau of China. Journal of Hydrology 381: 9-17. DOI:10.1016/j.jhydrol.2009.09.042.

Wang Y, Ma S, Zhu Y, Liu Z. 2011b. Impacts of land use and plant characteristics on dried soil layers in different climatic regions on the Loes Plateau of China. Agricultural and Forest Meteorology 151: 437-448. DOI:10.1016/j.agrformet.2010.11.016.

Wang Z, Liu B, Zhang Y. 2009. Soil moisture of different vegetation types on the Loess Plateau. Journal of Geographical Sciences 19: 707-718. DOI:10.1007/s11442-009-0707-7.

Western AW, Grayson RB, Blöschl G, Willgoose GR, McMahon TA. 1999. Observed spatial organization of soil moisture and its relation to terrain indices. Water Resources Research 35: 797-810. DOI:10.1029/ 1998WR900065.

Yang L, Chen L, Wei W. 2015. Effects of vegetation restoration on the spatial distribution of soil moisture at the hillslope scale in semi-arid regions. Catena 124: 138-146. DOI:10.1016/j.catena.2014.09.014.

Yang L, Chen L, Wei W, Yu Y, Zhang H. 2014a. Comparison of deep soil moisture in two re-vegetation watersheds in semi-arid regions. Journal of Hydrology 513: 314-321. DOI:10.1016/j.jhydrol.2014.03.049.
Yang L, Wei W, Chen L, Chen W, Wang J. 2014b. Response of temporal variation of soil moisture to vegetation restoration in semi-arid Loess Plateau, China. Catena 115: 123-133. DOI:10.1016/j.catena.2013.12.005.

Yang L, Wei W, Chen L, Mo B. 2012. Response of deep soil moisture to land use and afforestation in the semi-arid Loess Plateau, China. Journal of Hydrology 475: 111-122. DOI:10.1016/j.jhydrol.2012.09.041.

Yao X, Fu B, Lü Y, Chang R, Wang S, Wang Y, Su C. 2012. The multiscale spatial variance of soil moisture in the semi-arid Loess Plateau of China. Journal of Soils and Sediments 12: 694-703. DOI:10.1007/ s11368-012-0481-5.

Yu Y, Wei W, Chen L, Jia F, Yang L, Zhang H, Feng T. 2015. Responses of vertical soil moisture to rainfall pulses and land uses in a typical loess hilly area, China. Solid Earth 6: 595-608. DOI:10.5194/ se-6-595-2015

Zeng C, Shao M, Wang Q, Zhang J. 2011. Effects of land use on temporalspatial variability of soil water and soil-water conservation. Acta Agriculturae Scandinavica Section B-Soil and Plant Science 61: 1-13. DOI:10.1080/09064710903352589.

Zhang R, Cao H, Wang Y, Huang C, Tan W. 2012. Spatial variability of soil moisture and its influence factors in watershed of gully region on the Loess Plateau (in Chinese). Research of Soil and Water Conservation 19: $52-58$.

\section{SUPPORTING INFORMATION}

Additional supporting information may be found in the online version of this article at the publisher's web site. 